\title{
С.Л. Франк
}

\section{КОНСПЕКТЫ ЛЕКЦИЙ О РУССКОЙ ДУХОВНОЙ КУЛЬТУРЕ \\ (Публикация, подготовка текста и примечания А.А. Гапоненкова)}

मे

Ссылка для цитирования: Франк С.Л. Конспекты лекций о русской духовной культуре (Публикация, подготовка текста и примечания А.А. Гапоненкова) // Философические письма. Русско-европейский диалог. 2021. Т. 4, № 1. С. 222-233.

DOI: $10.17323 / 2658-5413-2021-4-1-222-233$

\section{Своеобразие русс $<$ кой $>$ мысли $^{1}$}

Ожидание громкого «нового слова». - Вместо него - осуществл<ение> социализма - пугало для народов. Наказание за гордыню и за пренебрежение к истинн<ому> национ<альному> духу. «Новое слово» - не единичное громкое Слово, а дух и своеобразие национ<альной> мысли. Внимание Европы к России и невнимание самих русских. - Если мы верим в реальность России, то мы должны верить в русскую мысль. Несколько формальных штрихов.

1) Русск<ая> мысль имеет свой критерий истины. Разъяснение: разн<ые> критерии в отнош<ении $>$ разн $<$ ых $>$ областей. Английск $<$ ий $>$ эмпиризм. Франц<узский> рационализм. Русск<ая > мысль: антирационализм - не иррационализм. Способность к научн<ому> знанию: спекулятивное дарование и трезвость. Пушкин. Антирац<ионализм> - истина не в логических связях. Onыт как жизненный опыт. Сковорода. Киреевский и идея живого знания. Вл. Соловьев и его фил<ософия > религии.

2) Онтологизм и реализм - исхожд<ение> из бытия. Идеализм западноевроп<ейской> мысли. Борьба с ним в русск<ой> философии. Cogito

В публикации подчеркнутые слова выделены курсивом, недописанные части слов взяты в угловые скобки. Правописание в основном приведено к современным нормам.

${ }^{1}$ Bakhmeteff Archive of Russian and East European History and Culture, Rare Book \& Manuscript Library, Columbia University, New York. S.L. Frank Papers. Box 12. Svoeobrazie russkoi mysli. 2 p. (lecture). Черновой автограф. Лекция под этим заглавием была прочитана в «Русском Доме» Варшавы 26 сентября 1927 года, в то время, когда Франк принимал участие во втором польском философском конгрессе (см. заметку: В «Русском Доме» // Руль. 30 сентября 1927. № 2079. С. 3). 
ergo sum. Кант - верховенство знания. Русск<ая> точка зрения - бытие. Мы в бытии. Религия. Спор о вере и делах - по-русски спасает Бог. Августино-пелаг<ианский $>$ спор о благодати и свободе волиㄹ. Русск<ая $>$ точка зрения - бытие человека в Боге.

3) Соборность. Очищение понятий. Славянофилы, хоровое начало, община. Ложность. Свойств<енная> русск<ому> человеку свобода личности, индивидуализм. «Я» и «мы». Хомяков и его теория церкви. Соборность и социализм - их противо-

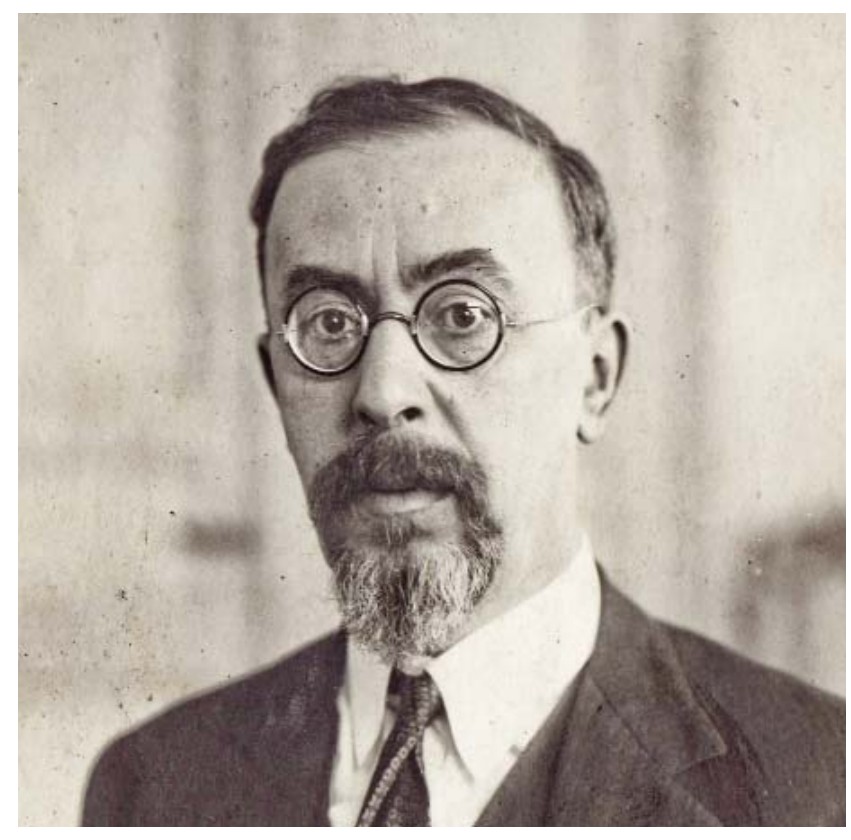

Семен Людвигович Франк (1877-1950) положность.

Трудность политич<еского> осущ<ествления > соборности. Политич<еская> несостоят<ельность $>$ русск<ой> мысли - из трудности сочетания универсализма с индивидуализмом. Великое прошлое религиозн $<$ ой $>$ государственности.

4) Область практики. Связь теории с практик<ой> во всяком миросозерцании. Особо практич<еский> характер русск<ого > мирос<озерцания>. - «Правда». Религиозн<ая> истина. Стремление к цельной истине. Связь с нигилизмом. Большевизм как чист<ый> нигилизм. Укорененность нигилизма в русской мысли. Все или

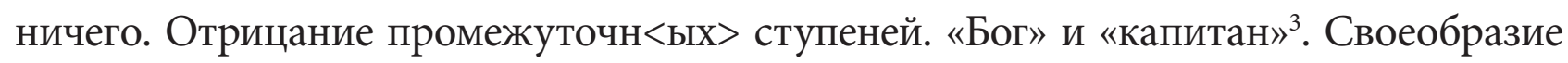
русск< ого > нигилизма - не скепсис, а вера в ничто, страсть и ничто, «штурм небес» ${ }^{4}$. Ужасно, но и утешительно. Глубина падения свидет<ельствует> о размахе духа. -

5) Религ <иозная $>$ философия. Своеобразн<ая $>$ связь космоса и человека. Космич<еский $>$ характер. Богородица и мать сыра земля ${ }^{5}$. Тютчев.

\footnotetext{
${ }^{2}$ Речь идет о споре между Бл. Августином и Пелагием (наст. имя Морган, церковный деятель из Британии) в V веке н.э. Первый считал благодать единственным источником спасения, второй допускал возможность спасения без ее помощи. Церковь приняла точку зрения Августина, но допустив участие человеческой воли в спасении.

${ }^{3}$ См. слова Лебядкина из романа Достоевского «Бесы» (часть 2, глава 1): «Если Бога нет, то какой же я после того капитан?» (Достоевский, 1974: 180).

${ }^{4}$ Имеется в виду сборник (Валентинов, сост., 1925).

${ }^{5}$ Персонифицированный образ Земли в славянской мифологии, богиня плодородия, мать всего живого. Здесь имеется в виду этот образ в романе Достоевского «Бесы» как выражение идеологии почвенничества. Хромоножка пересказывает пророчества «старицы»: «Так, говорит, богородица - великая мать сыра земля есть, и великая в том для человека заключается радость» (Достоевский, 1974: 116).
} 
Человеч<еский> характер. Философия человека. Судьба человека. Вел<икие> русские мыслители.

Вера и любовь к русской мысли'.

\section{Религиозное начало в русской мысли}

Значение русск<ой> мысли, национ<ального > начала для духовн<ого $>$ развития. Не отвлеч<енный> образец для нарочитого подражания, а живая основа. Индивид<уальное> и национ<альное $>$ «я». -

Великая русская художеств<енная> литература. Откуда? Худож<ественные> дарования не объясняют. Особый реализм русск<их $>-$ последняя правда. Это и

${ }^{6}$ На обороте листа добавлена карандашная запись: «Духовность непротиворечит практичности. Мы наказаны за наши грехи. Высочайшее находилось в пренебрежении.

Живое знание не значит быть крепким задним умом. Эмпиризм не значит пренебрежение наукой, мыслью.

Анархизм не противоречит соборности, а лишь социализму.

Московск<ое > государство научилось уханов - но они были великими госуд<арственными> деятелями. - Алекс<андр> Невский?»

${ }^{7}$ Bakhmeteff Archive of Russian and East European History and Culture, Rare Book \& Manuscript Library, Columbia University, New York. S.L. Frank Papers. Box 12. Religioznoe nachalo v russkoi mysli. 4 p. (lecture). Черновой автограф. Доклад по этому конспекту «Религиозные основы русской мысли» был сделан в Саарове на местном съезде РСХД в Германии 25 мая 1929 года. В репортаже Берлинца (псевдоним не раскрыт) «Россия в Саарове», опубликованном в «Вестнике РСХД», изложено краткое содержание данного выступления: «Проф. Франк отмечает, что в вечерней беседе о задачах РСХД он почувствовал у некоторых чувство страха: “а правильно ли идет РСХД, соответствует ли оно духу русского человека в России?” Не следует подражать чемуто, не следует стремиться во что бы то ни стало стать такими, как русский в России. Прежде всего, нужно стремиться к Правде Божией, к той Правде Божией, которая необходима каждому человеку - личности единственной и совершенно неповторимой. Когда мы жили в России, были пропитаны русским духом, мы не ценили его достаточно. Мы видим, как интересуется Россией Европа, прежде всего русской литературой, искусством. Русская литература 19-го столетия явление действительно потрясающее, и она привлекает к себе иностранцев правдой. Ни в одной литературе мы не найдем такой правдивости, честности, реализма, как в русской литературе. Русский дух ищет, прежде всего, правды - последней правды и глубины. На примерах Гоголя, Толстого, Достоевского и русских мыслителей: Герцена, К. Леонтьева, Федорова - проф. Франк подтверждает свою мысль. Он заканчивает свой доклад мыслью о том, что атеизм будет всегда существовать, но в будущем он выльется в чистый цинизм. Задача же РСХД - стремление осуществить русскую правду в ее полноте. В последовавших после доклада оживленных прениях разбиралось утверждение С.Л. Франком того, что Каратаев из “Войны и мира” характерен для русского религиозного типа. Лаговский, Царевский, пр. Степун и др. указывали на безличность, теплоту Каратаева, утверждая, что не Каратаев характерен для русского сознания. Прения по вопросу, поднятому одним из участников съезда: существует ли в русской литературе тип, отвечающий идеалу православного человека, - продолжались уже за обедом и во время послеобеденного перерыва, вплоть до 5 часов вечера, когда начался доклад проф. Степуна» (Берлинец. Россия в Саарове // Вестник РСХД. 1929. № 8-9. С. 51-52). 
есть религ<иозное> начало. - Примеры: 1) Гоголь - не соц<иальный> сатирик, а обличитель пошлости жизни. Переписка с друзьями и рел<игиозный> кризис. 2) Толстой - художник и мыслитель - раздор между ними - но в обоих — искание «правдь». 3) Достоевский - обнажение последних глубин души и искание Бога. Лермонтов. - Русские мыслители: 1) Чаадаев - отвержение родины из-за ее непросвещенности. 2) Славянофиль - Киреевский и Хомяков - мечта о русской правде. 3) Гериен - разочар<ование> в Европе. 4) К. Леонтьев - добро как красота и полнота жизни. 5) Русский социализм - Белинский - искание правды.

Что такое религ<иозное> начало? Не всегда совпадает с религ<иозной> мыслью и верой. Мысли и слова о Боге - и чувство Бога ${ }^{8}$.

Два типа: 1) Тип русск<ого> святого - благостность, покой. Своеобр<азие> русской церкви в этом смысле. Платон Каратаев ${ }^{9}$. Пушкин как образец. 2) Жажда преображения мира - динамич<еский> тип. Достоевский. Федоров. Русский социализм и его внутренн<ее> противоречие (атеистич<еская> религия). Превращение противоположности этих типов в разрыв между верой и рел<игиозным> бунтарством, восстанием против Бога (антирелигиозность, не атеизм). Этот бунтарский атеизм, уничтожая живую душу, истребляет сам себя. Задача воссоединения и гармонического сочетания онтологизма с динамизмом. Оба начала в отдельности грозят вырождением - второй - в бесовство, первый - в мертвый индифферентизм. - Но первый есть фундамент.

С этим связана другая задача: осознания рел<игиозного> начала вообще. Его неосознанность в русск<ой> светской культуре ${ }^{10}$. Пушкин! Разрыв - Пушкин и Сер<афим> Саровский. Соответствовали одно время разрыву между высш<ими> и низш<ими> классами. Революция как следствие этого разрыва и как очистительный процесс. Неизбежность иельной культуры. Противоречия и борьба будут - но вдохновенного идеального атеизма не будет будет цинизм. Задача русс<кого $>$ студ<енческого $>\mathrm{xp}<$ истианского $>$ движения. Необходимость широты, универсальности, чтобы остаться верным $<$ и $>$ русс<кому> духу. Славянофилы и западники отчасти вообще совпадают с этими двумя типами.

8 Зачеркнуто: «Русское понятие “правды”. Определение Михайловского. Онтологизм Бог — основа бытия. Два русских духовн<ых> типа: 1) гармонический, утвержденный в Боге и 2) ищущий правды, потерявший ее непоср<едственное> ощущение».

${ }^{9}$ Персонаж романа Л.Н. Толстого «Война и мир».

10 Зачеркнуто: «Неосознанность рел<игиозного> начала в русск<ой> мысли XIX века (только Вл. Соловьев!) Разрыв - Пушкин и Серафим Саровский <...>». 


\section{Два течения русской мысли ${ }^{11}$}

Необходимость заново изучить ист <орию $>$ русск<ой $>$ мысли. Искажения и непонимание, страх излож<ить $>$ из-за политич <еского $>$ угла зрения.

Два течения - религиозно-мистическое и социально-радикальное. Их глубочайшая внутр<енняя> противоположность - и их сходство в выводах и практич<еских $>$ приложениях.

Радищев и Новиков. - «Я оглянулся окрест меня, и душа моя страданиями человечества уязвлена была» ${ }^{22}$. - Радикализм, зло - в учреждениях. - Новиков начинает с сатир <ических> журналов, но бичует нравы и пороки - масонство; Шварц и его борьба с франц<узским> духом ${ }^{13}$. Отзыв митр<ополита $>$ Платона о

${ }^{11}$ Bakhmeteff Archive of Russian and East European History and Culture, Rare Book \& Manuscript Library, Columbia University, New York. S.L. Frank Papers. Box 11. Dva techeniia v russkoi mysli. 3 p. (lecture). Черновой автограф. Предположительно, лекция (доклад?) по этому конспекту была прочитана Франком весной 1930 года в Русском научном институте в Белграде. На отдельной странице Франком записаны карандашом ответы на вопросы оппонентов:

«Евг<ению> Вас<ильевичу >: я не настаиваю на слове персон<альная> уния, но существо остается. - Я ограничился звездами первой величины (митр<ополит> Филарет пробл<ематика> церковной мысли). - Речь Достоевского - впечатление двойственное. “Соборность” имеет у меня определенный смысл и касается только мысли (недоразумение). В России эта близость гораздо ярче.

Мих<аилу> Ник. - Не личное совершенствование, а духовное воспитание - хотя бы общественное. “По плодам их узнаете” - расхождение в наше время! - Религия - реальность духовной жизни! Догмат<ическое> и критич<еское> - совсем иное!

Я аскетически воздержался от философии. Герцен - не просто либерал. Сходство с Ницше нельзя откомментировать - но есть внутр<енняя > связь.

Гоббс - материалист и большевик!

Психологич<ески> - но если тиипично, то становится историч<еским > своеобразием. В этом в 19 в. противоположн<ость > Европе. - В Евр<опе > - эпизод, в России - типич<ное> (романт <изм> немецк<ий>)».

Франком упомянут Евгений Васильевич Спекторский (1875-1951) - историк права, профессор и декан Русского юридического факультета в Праге (1927), профессор Карлова, Белградского, Люблинского университетов, член Русского исторического общества, первый председатель правления Русского научного института в Белграде (1928-1930). Вероятно, второй оппонент - Михаил Никитович Лапинский (1862-1947), ученый-невропатолог, доктор медицины (1897), профессор и зав. кафедрой нервных и душевных болезней Киевского университета Св. Владимира (1904-1918), профессор Загребского университета (1921-1946); публиковался в журнале «Записки Русского научного института в Белграде».

${ }^{12}$ См. точную цитату из книги А.Н. Радищева «Путешествие из Петербурга в Москву»: «Я взглянул окрест меня - душа моя страданиями человечества уязвленна стала» (Радищев, 1981: 12).

${ }^{13}$ Иван Григорьевич Шварц (1751-1784) - натурфилософ, профессор Московского университета, просветитель, сподвижник Н.И. Новикова. Боролся с «французским духом» в среде аристократии и вместо сочинений атеистов и материалистов предлагал читать Библию. 


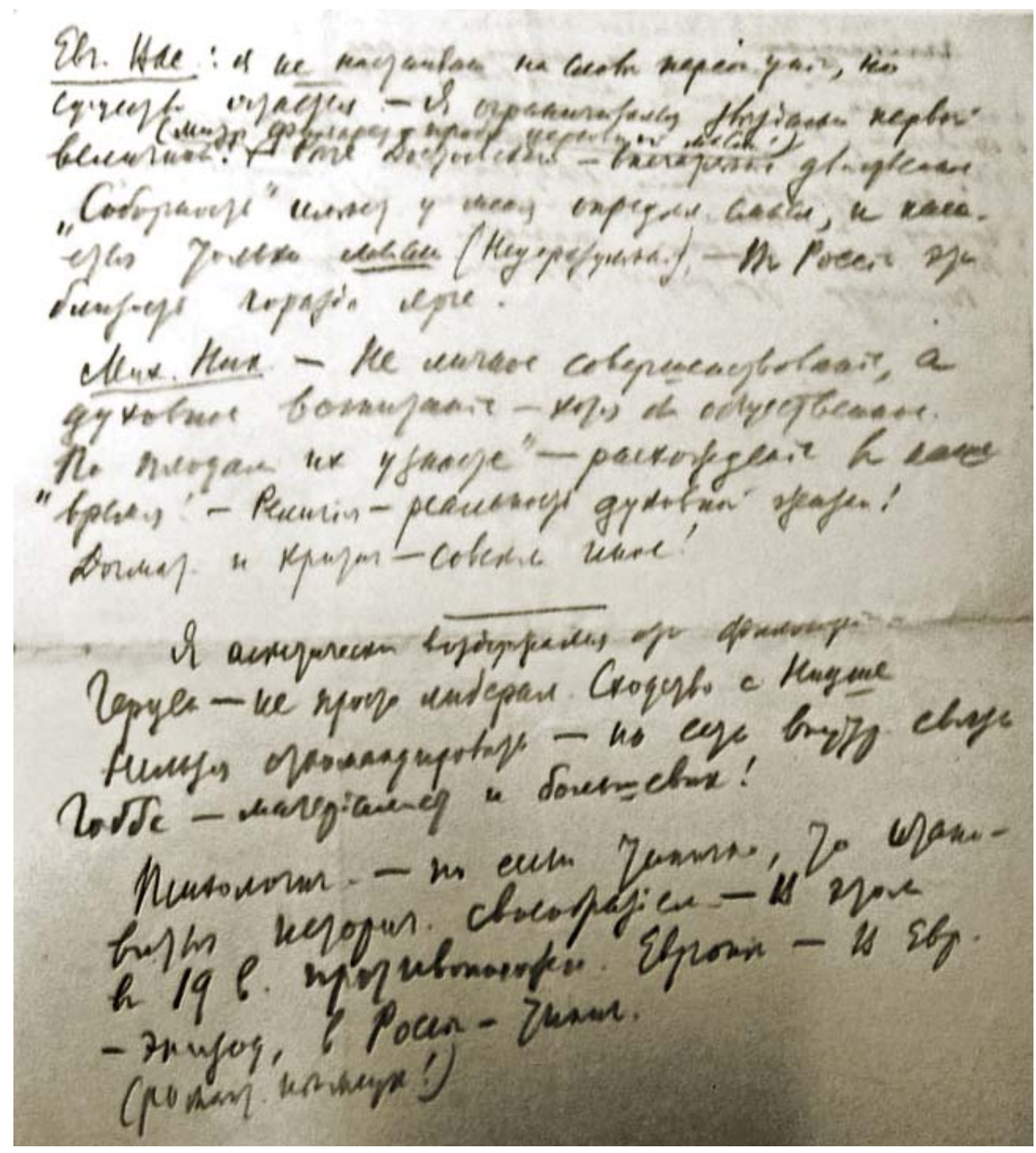

С.Л. Франк. Страница чернового автографа

с ответами на вопросы оппонентов

Новикове ${ }^{14}$ - и всё же: и правительство и общество смотрят одинаково: Екатерина «фармазон и вольтерианец» ${ }^{15}$. - Дальнейшая история: 1) персональная уния

${ }^{14}$ Платон (Левшин) (1737-1812) - митрополит Московский и Коломенский, писатель и проповедник; законоучитель наследника императорского престола. Речь идет об отзыве митрополита Платона, адресованного Екатерине II, по поводу возбужденного против Н.И. Новикова дела: «Я одолжаюсь по совести и сану моему донести Тебе, что молю всещедрого Бога, чтобы не только в словесной пастве, Богом и Тобой мне вверенной, но и во всём мире были христиане таковые, как Новиков» (цит. по: Лонгинов, 2000: 442).

${ }^{15}$ Выводы о том, что зло царит в российских учреждениях, официальной церкви и они должны быть идейно поколеблены в глазах общества, которому дорога - стремиться к “истинному просвещению” и прогрессу, привели к не менее радикальному отпору и обвинениям со стороны самодержавия, особенно после Пугачевского восстания и Французской революции. В общественном мнении России, совпавшем с правительственным, Радищев - «бунтовщик хуже Пугачева» (Екатерина II), Новиков — «фармазон и вольтерианец». 
двух течений: Чаадаев в молодости радикал, Герцен - верующий, Бакунин и Белинский - метафизики, Достоевский - петрашевец. Добролюбов - верующий, Вл. Соловьев - неверующий. - Новейший идеализм и религ<иозная> мысль из марксизма; 2) близость течений: а) кружок Станкевича - и кружок Герцена и Огарева, как выраж<ение> двух направлений. Но из станкев<ичевского > кружка вышли Белинский и Бакунин; в) славянофилы и западники - тесная связь между ними, отмечен<ная > Герценом ${ }^{16}$. Славянофильство в народничестве (Герцен, Бакунин и сл<авянофилы>). 3) Судьба в общественном мнении - та же, что у Новикова: Чаадаев - Вл. Соловьев - Толстой. 4) Внутренняя связь идей. Герцен как духовный тип. - Достоевский: сначала - чистый гуманист, потом религ <иозный> мыслитель, критика Белинского (смрадн $<$ ое $>$ явление) $)^{17}$, «Бесы». И всё же - Иван и Алёша - родн<ые> братья по духу; Алеша должен стать революционером ${ }^{18}$. - То же у Вл. Соловьева (приближение к просветительству, «падение средневекового миросозерцания» ${ }^{19}$ и Толстого. Один Конст. Леонтьев исключение.

Проблематика: русск<ая > религ<иозная > мысль социальна - Чаадаев, Достоевский, Толстой, Федоров; но именно поэтому она сбивается на социальный радикализм. - Евг. Трубецкой о новейшей русской философии - «политич<еское> доказ<ательство> бытия Бога» ${ }^{20}$.

${ }^{16}$ См.: «Да, мы были противниками их, но очень странными. У нас была одна любовь, но неодинакая. <...> И мы, как Янус или как двуглавый орел, смотрели в разные стороны, в то время как сердце билось одно» (Герцен, 1956: 170).

${ }^{17}$ Имеется в виду письмо Ф.М. Достоевского к Н.Н. Страхову от 18 (30) мая 1871 года: «Я обругал Белинского более как явление русской жизни, нежели лицо: это было самое смрадное, тупое и позорное явление русской жизни. Одно извинение - в неизбежности этого явления» (Достоевский, 1986: 215).

${ }^{18} \mathrm{O}$ том, как замыслил Достоевский будущую судьбу Алеши Карамазова, находим в «Дневнике» А.С. Суворина: «Тут же он сказал, что напишет роман, где героем будет Алеша Карамазов. Он хотел его провести через монастырь и сделать революционером. Он совершил бы политическое преступление. Его бы казнили. Он искал бы правду и в этих поисках, естественно, стал бы революционером...» (Суворин, 1990: 391).

${ }^{19}$ Имеется в виду нашумевший доклад Вл. С. Соловьева «Об упадке средневекового миросозерцания» (1891) (Соловьев, 1988), после которого ему запретили выступать с публичными лекциями. Философ подверг жесточайшей критике византийскую цивилизацию, «псевдохристианский индивидуализм», который есть «падение средневекового миросозерцания». Империя ромеев не смогла совместить «мирское царство» и «Царство Божие». «Идея общественности» была отринута, и социальный строй Византии оставался языческим, что явилось причиной гибели этого государства.

${ }^{20}$ Источник цитаты не обнаружен. Философ Е.Н. Трубецкой, «один из самых благородных сторонников идеи христианского возрождения общественной жизни» (Франк, 1965: 137), искал религиозного обоснования политических идей, был трезвым реалистом в политике. 
Два столкновения: 1) Переписка Гоголя и письмо Белинского. 2) «Вехи»! Их историч<еское> значение.

Пересмотр традиций одинаково необходим.

\section{Русская дух<овная> культура ${ }^{21}$}

Эмиграция - состояние внешн<ей> бытовой беспочвенности. Искание почвы, точки опоры. Интерес к тому, что делается в России. Она может быть только внутренней, духовной. Русск<ий> язык, литература, искусство, религия. - От врем<ени> до времени надо это инстинкт<ивное> чувство стараться осмыслить, понять. - Дело не в нарочитом национализме (который ложен), а в свободном желании найти почву для личности.

Русская духовная культура 19 века и ее значительность. Прежние поколения остро и даже преувеличенно чувствов<али> ее недочеты; теперь - жажда открыть ее ценность. Адекватн<ое> отношение - объективное. Необходимо осмисслить состояние русск<ой $>$ духовной культуры ${ }^{22}$.

Попытка синтетич<ески > изобразить основные черты русск<ой $>$ культ $<$ уры $>$ 19 в. (читаю немцам, но полезно и русским).

Две основные черты: 1) своеобразное сожительство и схождение двух mечений - религиозного и атеистически-социально-политическ<ого>; 2) разрыв между образованным классом и народом.

I. 1) К истории: Радищев и Новиков, энциклопедизм французск<ий> и немецк<ая> мистика. - В 30-х годах - кружок Станкевича и кружок Герцена. - В 40-х - славянофилы и западники. - Столкновение между Гоголем и Белинским. Далее: линия Достоевского, Толстого, К. Леонтьева, Вл. Соловьева - и линия нигилизма, народничества и револ<юционного > социализма. Впервые окончательное опознание противоположности - в «Вехах» $1909<\Gamma>$.

2) Внутренняя противоположность и внешнее сродство. «Вольтерианцы и фармазоны». Отношение Екатерины к масонству (революционеры!). - Судьба Чаадаева. - Славянофилы и западники - «братья» (Герцен). Правит<ельство> Николая I преследует славянофилов. - Достоевский и двойств<енность> отношения: «Бесы» И «Бр<атья> Карамазовы» (сродство Алеши и Ивана - социализм

\footnotetext{
${ }^{21}$ Bakhmeteff Archive of Russian and East European History and Culture, Rare Book \& Manuscript Library, Columbia University, New York. S.L. Frank Papers. Box 12. Russkaia dukhovnaia kul'tura. 2 p. (lecture). Черновой автограф.

${ }^{22}$ На полях: «Судьба русск<ой> культуры. Понять - можно только исторически».
} 
и Бог. Судьба Алеши в ненапис<анной> части романа) $)^{23}$. Тип Толстого. - Два варианта марксизма (Струве и Ленин).

3) Откуда этот парадокс? Два источника: 1) бессознат<ельная > религиозность русск<ого> атеизма - Герцен, Белинский, Добролюбов. Искание правды Божией; 2) общественные искания религиозного типа: Чаад<аев>, славянофилы, Достоевский - из идей обожения, преображения мира. Тип русского интеллигенma: бескорыстн<ый> искатель правды и бунтарь, гордый спаситель мира. Но это остается неосознанным.

II. Разрыв. Народ как сфинкс (Тургенев) $)^{24}$. Некрасов («В столицах шум...») ${ }^{25}$. Чеховский рассказ ${ }^{26}$. - Беспокойство. Славянофильство и народничество - поклонение простому народу. - В чем смысл:

1) Социальный разрыв - дворянство и крестьянство, отсутствие промежут<очного > звена.

2) Культурный разрыв - после Петра - западн <ическая > образов<анность > и исконно православная духовн<ая> культура (попытки соединения у Гоголя, славянофилов не достигают цели).

Революция как итог - крушение надломленного.

Итоги революции. - 1) Ясный водораздел между религиозн<ым> и атеист <ическим $>$ направл<ениями $>$ с торжеством циническ<ого $>$ материализма. (По плодам узнаете их! ${ }^{27}$ 2) Конеи, разрьвва - единство культуры. Точнее, разрыв в друг <ом> напр<авлении > - не два, а только один (первый).

Творческие задачи русск<ой> мысли теперь и в России, и здесь, за рубежом. Охрана традиций русск<ой> мысли и отказ от ее заблуждений. Величайшая задача нового строительства духовного (существеннее, чем чисто внешнее строительство). Жестокость нынешн<его> кризиса - царство Антихриста, обращение революции против народа (колхозы и религ <иозные $>$ преследов $<$ ания $>$ ). Задачи эмиграции в силу свободы мысли. Наша лень и уныние. Русск<ое> студ<енческое > христ<ианское > движение - как попытка организации творческ<ой> духовн<ой> силы - не сектантство, а широчайшие задачи.

\footnotetext{
${ }^{23}$ См. примеч. 17 к конспекту «Два течения русской мысли».

${ }^{24}$ Имеется в виду стихотворение в прозе И.С. Тургенева «Сфинкс» (1878).

${ }^{25}$ См. стихотворение Н.А. Некрасова «В столицах шум, гремят витии...» (1858).

${ }^{26}$ Имеется в виду повесть А.П. Чехова «Мужики» (1897).

${ }^{27}$ Из Евангелия от Матфея: «По плодам их узнаете их» (Мф. 7:16).
} 


\section{Литература}

Валентинов, сост., 1925 - Черная книга («Штурм небес»). Сборник документальных данных, характеризующих борьбу советской коммунистической власти против всякой религии, против всех исповеданий и церквей / сост. А.А. Валентинов; вводная ст. П. Струве. Париж: Изд. Русского национального студенческого объединения, 1925. 294 с.

Герцен, 1956 - Гериен А.И. Былое и думы. Часть IV // Гериен А.И. Собр. соч. в 30 т. М.: Изд-во Акад. наук СССР, 1954-1966. Т. IX. 1956. С. 5-262.

Достоевский, 1974 - Достоевский Ф.М. Полн. собр. соч.: В 30 т. Л.: Наука. Ленингр. отд-ние, 1972-1990. Т. 10: Бесы. Роман. В 3 ч. 1974. 519 с.

Достоевский, 1986 - Достоевский Ф.М. 428. Н.Н. Страхову. 18 (30) мая 1871. Дрезден // Достоевский Ф.М. Полн. собр. соч.: В 30 т. Л.: Наука. Ленингр. отд-ние, 1972-1990. Т. 29, кн. 1: Письма, 1869-1874. 1986. С. 214-217.

Лонгинов, 2000 - Лонгинов М.Н. Новиков и московские мартинисты. СПб.: Лань; С.-петерб. Ун-т МВД России; Фонд «Университет», 2000. 658 с.

Радищев, 1981 - Радищев А.Н. Путешествие из Петербурга в Москву. Л.: Худож. лит., 1981.200 с.

Соловьев, 1988 - Соловьев В.С. Об упадке средневекового миросозерцания // Соловъев В.С. Соч. в 2 т. М.: Мысль, 1988. Т. 2. С. 339-350.

Суворин, 1990 - Суворин А.С. Из «Дневника» // Ф.М. Достоевский в воспоминаниях современников: В 2 т. М.: Худож. лит., 1990. Т. 2. С. 390-391.

Франк, 1965 - Франк С.Л. Из истории русской философской мысли конца XIX и начала XX века: Антология / посмертная ред. В.С. Франка. Washington; New York: Inter-language literary assoc., 1965. 299 c.

(C) 2021 А.А. Гапоненков (публикация, подготовка текста и примечания) 
S.L. Frank

\section{ABSTRACTS OF LECTURES ABOUT RUSSIAN SPIRITUAL CULTURE \\ (Publication, preparation of the Text and the Notes by A.A. Gaponenkov)}

W

For citation: Frank, S.L., 2021. Abstracts of Lectures about Russian Spiritual Culture (Publication, preparation of the Text and the Notes by A.A. Gaponenkov). Philosophical Letters. Russian and European Dialogue, 4(1), 222-233. (in Russ.)

DOI: $10.17323 / 2658-5413-2021-4-1-222-233$

\section{References}

Dostoevskii, F.M., 1974. Polnoe sobranie sochinenii [Complete Works]. 30 vols. Vol. 10. Leningrad: Nauka. Leningradskoe otdelenie Publ.

Dostoevskii, F.M., 1986. 428. N.N. Strakhovu. 18 (30) maya 1871. Drezden [428. To N.N. Strakhov. 18 (30) May 1871. Dresden]. In: Dostoevskii, F.M. Polnoe sobranie sochinenii [Complete Works]. 30 vols. Vol. 29, book 1. Leningrad: Nauka. Leningradskoe otdelenie Publ. 214-217.

Frank, S.L., 1965. Iz istorii russkoi filosofskoi mysli kontsa XIX i nachala XX veka: Antologiya [From the history of Russian philosophical thought of the late $19^{\text {th }}$ and early $20^{\text {th }}$ centuries: Anthology]. Posthumous ed. by V.S. Franck. Washington; New York: Inter-language literary association.

Gertsen, A.I., 1956. Byloe i dumy. Chast' IV [Past and Thoughts. Part IV]. In: Gertsen, A.I. Sobranie sochinenii [Collected Works]. 30 vols. Vol. IX. Moscow: Academy of Sciences of the USSR Publ. 5-262.

Longinov, M.N., 2000. Novikov i moskovskie martinisty [Novikov and the Moscow martinists]. St Petersburg: Lan'; Sankt-peterburgskii Universitet MVD Rossii; Fond 'Universitet' Publ.

Radishchev, A.N., 1981. Puteshestvie iz Peterburga v Moskvu [Travelling from St Petersburg to Moscow]. Leningrad: Khudozhestvennaya literature Publ.

Solov'ev, V.S., 1988. Ob upadke srednevekovogo mirosozertsaniya [On the decline of the medieval world outlook]. In: Solov'ev, V.S. Sochineniya [Works]. 2 vols. Vol. 2. Moscow: Mysl' Publ. 339-350. 
Suvorin, A.S., 1990. Iz "Dnevnika” [From “The diary”]. In: F.M. Dostoevskii v vospominaniyakh sovremennikov [F.M. Dostoevsky in the memoirs of his contemporaries]. 2 vols. Vol. 2. Moscow: Khudozhestvennaya literature Publ. 390-391.

Valentinov, A.A. ed., 1925. Chernaya kniga ("Shturm nebes"). Sbornik dokumental'nykh dannykh, kharakterizuyushchikh bor'bu sovetskoi kommunisticheskoi vlasti protiv vsyakoi religii, protiv vsekh ispovedanii i tserkvei [Black book ("Storm of heavens"). The collection of documentary data, characterizing the struggle of the Soviet communist government against any religion, against all confessions and churches]. Introductory article by P. Struve. Parizh: Izdatel'stvo Russkogo natsional'nogo studencheskogo ob"edineniya Publ.

(C) 2021 A.A. Gaponenkov (Publication, preparation of the text and the notes) 